\title{
A atuação do design nos processos de divulgação científica: a Metodologia do Mapeamento Prévio
}

Délcio Julião Emar de Almeida;

Rita Aparecida da Conceição Ribeiro

resumo:

O presente artigo discute o papel do Design nos processos de construção de estratégias de divulgação científica. São apresentadas definições do que seja a divulgação da ciência, sua relação com o Design e as interseções entre os processos metodológicos que caracterizam as áreas tanto do Design quanto da Ciência. Para tal, será apresentada a proposta da Metodologia do Mapeamento Prévio, desenvolvida a partir da Teoria do Mapeamento Estrutural pertencente à área da psicologia cognitiva, concebida inicialmente para analisar as abrangências e limitações das analogias, utilizadas em processos de ensino e aprendizagem. Dessa forma, propõe-se o desdobramento do mapeamento de relações analógicas para a concepção de modelos para a divulgação de conceitos científicos. Serão apresentados resultados preliminares da aplicação da referida metodologia.

palavras-chave:

Design; Metodologia do Mapeamento Prévio; divulgação científica; metodologia de projeto; Teoria do Mapeamento Estrutural 


\section{Divulgação científica: conceitos e atuação}

O termo Divulgação cientifica se baseia nas estratégias de levar à sociedade conceitos de interesse científico, de forma clara, instigante e palatável. Tais estratégias reduzem a distância entre os produtores do conhecimento e a opinião pública, por meio de ferramentas de comunicação. Os museus de ciência, jornalismo científico, peças de teatro, literatura e documentários são apenas alguns exemplos que como informações científicas podem chegar ao público não iniciado, transformando a forma de se observar o mundo e influindo opiniões a respeito de temas polêmicos advindo do campo da ciência.

Assuntos relacionados à saúde, tecnologia e meio ambiente assumem papel de destaque nas discussões cotidianas, em meio a opiniões e pareceres desconexos e, muitas vezes, afastados da realidade, gerando mais confusão do que esclarecimento. Outras vezes, a divulgação de conteúdos científicos se presta ao papel de favorecer interesses econômicos e políticos, sem necessariamente estarem alinhados com o bem-estar da sociedade para a qual se direcionam. Morin (2015) alerta para o que nomeia como patologia da razão e à inteligência cega, obliteradoras que são da possibilidade da formação do pensamento complexo em relação aos conhecimentos, sistemas e relações de poder que caracterizam as sociedades contemporâneas.

Piassi et al (2013) argumentam a necessidade de estratégias consistentes de democratização de conceitos de interesse científico, imprescindíveis na formação de um público bem informado, proporcionando, consequentemente, o interesse por tais temas e o impacto na sociedade. Dessa forma, um processo de divulgação científica se caracteriza não apenas como a tradução, mas antes a recriação de conhecimentos antes reservados a um grupo restrito, ampliando seu escopo de atuação, por meios de estratégias comunicacionais diversas (ALBAGLI, 1996; MORA, 2003; MARANDINO \& DÍAZ ROCHA, 2009). Essa recriação valoriza a dúvida, o questionamento, priorizando o debate e afastando certezas, as quais podem prejudicar processos de decisão ao invés de promover o debate crítico a respeito de temas de interesse de toda sociedade, conforme argumenta Silva Jr. (2017).

Bueno (1988, p.19) afirma que a divulgação científica "pressupõe um processo de recodificação, isto é, a transposição de uma linguagem especializada para uma linguagem não especializada, com objetivo de tornar o conteúdo acessível a uma vasta audiência”. Observa-se, portanto, a necessidade de se discutir e ampliar essas estratégias de transposição semântica e estrutural, no sentido de ampliar o acesso do público em geral a esses conteúdos, pois, de acordo com Targino (1998, p.6), somente assim será possível aprimorar o olhar crítico, compartilhando conhecimento, pois "a ignorância e a mediocridade repousam na incapacidade de gerar e acalentar incertezas".

Silva (2006) argumenta que a divulgação científica se dá por meio de vários mecanismos, caracterizados por diversos textos e formas. Tais estratégias se enquadram em um leque tão ampliado quanto diversas são as possibilidades, assim como o são os grupos sociais para as quais se destinam:

Dificilmente se poderia dizer o que é e o que não é divulgação científica nesse conjunto. Parece que o termo divulgação científica, longe de designar um tipo específico de texto, está relacionado à forma como o conhecimento científico é produzido, como ele é formulado e como ele circula numa sociedade como a nossa. (SILVA, 2006, p.53)

Devido ao advento das redes sociais, a disseminação de informações está ocorrendo em uma escala sem precedentes na história, ampliando o acesso, mas, por outro lado, contribuindo para que pseudociências e informações equivocadas sejam compartilhadas, tais como terraplanismo, disseminação de notícias falsas contra as vacinas, uso de medicamentos sem comprovação ou aprovação médica, automedicação dentre outras desinformações. Ocorre, portanto, a reverberação em diversos níveis da sociedade, afetando grande parcela da população, influenciando sobremaneira a forma de se perceber e considerar o produto da pesquisa científica.

Existe a preocupação na interlocução de conteúdos de interesse científico, ou seja, o caminho de diálogo entre o produtor do conhecimento e o público em geral. Seria o cientista, o pesquisador, o detentor do status de divulgador da ciência, pelo fato de ser especialista? Esse sujeito seria habilitado, por ser conhecedor das linguagens e conteúdos próprios da ciência, o sujeito ideal para transmiti-la ao 
público? Mora (2003) alerta a respeito da polissemia de estratégias e linguagens que podem ser utilizadas para os processos de divulgação científica, sendo que cada divulgador lançará mão de estilos distintos, os quais variarão de acordo com os interesses que subjazem no processo. Dessa forma, segundo a autora, o ideal seria discutir porque se faz divulgação científica. Essa discussão apontaria, portanto, como deveria ser feita, dependendo do seu intento. Sugere, portanto, que existem basicamente dois porquês de se consumir conhecimento científico: a necessidade e o prazer. A necessidade se dá pelo fato de que a informação inclui e, um sujeito desinformado pode ser excluído dos processos discursivos e decisórios no corpo das demandas sociais. Além disso, existe o risco de se tomar atitudes equivocadas e até perigosas no que tange a saúde e a segurança, com exemplos sintomáticos observados diuturnamente nas já referidas redes sociais. Por outro lado, o prazer advém do sentimento de pertença e cidadania, ao despertar o poderoso grau estético de se conhecer a ciência, para além do seu valor utilitário. Ou seja, o significado surge quando o indivíduo consegue conectar os conteúdos científicos com seu cotidiano (MORA, 2003).

Essas reflexões apontam para a importância de se pensar em estratégias que combinem linguagens palatáveis e atraentes, unindo arte e tecnologia para se falar de Ciência. Neste ponto, o Design se apresenta como campo propício para se discutir tais estratégias, apesar de que, nas propostas acadêmicas que abordam a divulgação da ciência, observou-se que o termo Design é adotado na abordagem de questões ligadas às dimensões estruturais e estéticas do projeto visual, propostas editoriais de revistas científicas e o papel das imagens na disseminação da ciência (PASSOS et al, 2014; PEREIRA et al, 2015; CAMPOS, 2016). Portanto, argumenta-se qual seria o papel do Design como área de articulação do conhecimento, possibilitando a emersão de produtos e estratégias transdisciplinares no âmbito da divulgação científica e do ensino e aprendizagem.

A dimensão transdisciplinar do Design pode ser observada nas diversas áreas do saber que lhe aportam o campo de atuação, se caracterizando, cada vez mais, no desenvolvimento de estratégias que buscam a interação de pessoas, saberes e recursos para a concepção de sistemas possuidores de valores focado no indivíduo, coautores do processo de criação (BUCHANAN, 2001; ALEXANDRE et al, 2019). Nessa mesma direção, Costa Jr (2017) argumenta que o Design deve ser visto como uma área envolvida diretamente em questões sociais, culturais e políticas, se caracterizando como um fenômeno social. Portanto, a proposta dessa pesquisa é propor uma metodologia que alinhe os processos do Design com as diversas áreas do saber, em particular a Ciência, no sentido de fornecer uma ferramenta que potencialize a concepção de estratégias de divulgação científica, envolvendo todos os atores no processo criativo. O caminho escolhido foi adotar a Teoria do Mapeamento Estrutural, de Dedre Gentner ${ }^{1}$, como guia para tal proposição.

\section{A Teoria do Mapeamento Estrutural}

Os processos cognitivos estão entrelaçados com os conceitos relacionados aos processos de raciocínio dedutivo, indutivo e abdutivo. A indução se refere às dinâmicas de demonstrar, por meio da experimentação, como um fenômeno pode ser percebido, levando à confirmação ou não de uma teoria, ou seja, parte do particular para se propor uma generalização. A dedução busca entender a natureza de um fenômeno por meio de premissas e generalidades, indo do geral para o particular. Por outro lado, a abdução possibilita a introdução de generalidades aos juízos particulares. Está associado aos processos heurísticos que caracterizam o pensamento criativo, antecipando a concepção de hipóteses, de acordo com Peirce (2005).

No campo das ciências, Popper (2006) propõe, ainda, o pensamento hipotético-dedutivo, o qual se baseia na tentativa de reduzir ou mesmo eliminar possíveis equívocos de uma hipótese, por meio do falseamento da mesma. Parte de um problema e uma hipótese inicial, provisória, que é submetida a testes que, na verdade, criariam outros problemas e hipóteses, resultantes da eliminação dos erros iniciais apontados no processo de falseamento. Resumindo, o levantamento de novas

\footnotetext{
${ }^{1}$ Dedre Gentner é professora e pesquisadora do Departamento de Psicologia da Northwestern University (Estado de Illinois, EUA). Suas pesquisas na área de Psicologia Cognitiva se direcionam principalmente aos processos de raciocínio por analogias e sua relação com a aprendizagem humana.
} 
hipóteses provisórias se dá pelo pensamento dedutivo que, submetidas a testes - indução - levarão à refutação ou aceitação dessas hipóteses.

Observa-se, portanto, que os referidos processos de raciocínio são objeto de estudo da Psicologia Cognitiva que, em linhas gerais, segundo Quelhas \& Juhos (2013), busca estudar como se dá o processo de internalização das informações captadas no meio - exteriores ao indivíduo - e sua posterior recodificação, retornada ao ambiente. Dentre os estudos da Psicologia Cognitiva, encontrase a proposta da Teoria do Mapeamento Estrutural - TME (Gentner, 1983) que busca avaliar as abrangências e limitações das analogias utilizadas nos processos de raciocínio e construção do conhecimento.

\subsection{Analogias e modelos analógicos}

O raciocínio por analogias caracteriza o pensamento humano. Segundo Gombrich (1995), fazer comparações é o que permite a humanidade criar arte e ciência, em todo o seu trajeto histórico. Observar o mundo dos fenômenos, contrapor aparências, similaridades e distinções, alavancou a espécie humana na sua trajetória evolutiva. Assim se caracteriza o pensamento por analogias, as quais permitem que conhecimentos se tornem mais acessíveis, principalmente conceitos científicos, conforme argumenta Terrazzan et al. (2005). No que se refere aos processos de compartilhamento e construção do conhecimento, ensino e aprendizagem, as analogias se apresentam como ferramentas estratégicas importantes (GLYNN, 1994; NAGEM et al.,2001; OLIVA et al, 2005; BOZZELI \& NARDI, 2006; MOZZER \& JUSTI, 2015). Uma analogia, portanto, estabelece a correspondência explícita entre dois corpos de conhecimentos, denominados por Gentner (1983) como domínios. Um dos domínios é a base (DB) para se estabelecer a comparação, no qual se buscará as comparações analógicas. Portanto, é um domínio familiar. No outro extremo, encontra-se o domínio alvo (DA), pouco familiar, que será o motivo da comparação. Um conceito científico, por exemplo, pode ser considerado um DA, por se apresentar, de acordo com a situação em que se coloca o raciocínio analógico, como a entidade de interesse científico que se quer compreender.

Atrelado ao conceito de analogias, encontra-se o termo modelo, o qual, para os propósitos dessa pesquisa, será definido como uma representação parcial de uma entidade de interesse científico, de acordo com Mozzer \& Justi (2015). Um modelo busca, portanto, estabelecer relações de similaridade com essa entidade, a partir de um processo de modelagem - concepção e construção - e se portarão como mediadores do conhecimento. Um modelo é caracterizado por um conjunto de afirmações - aparência, funções, dentre outras - que podem se conectar com o DA que será representado por esse modelo. Essa conexão se dará, muitas vezes, por meio das relações analógicas DB - entre o modelo e o DA. Vale alertar que nem sempre essa conexão pode ser classificada como uma relação de analogias, já que a similaridade entre o modelo e a entidade modelada - DA que passou pelo processo de modelagem - não implicará, necessariamente, em uma relação analógica (FERRY, 2018). O processo de modelagem, portanto, se refere à concepção de modelos, sua criação e construção, dependendo das intenções para as quais o modelo se destina. Entretanto, nem sempre um modelo será análogo ao DA, conforme citado anteriormente.

No sentido de clarear os conceitos anteriormente apresentados, tem-se o exemplo da representação das camadas geológicas do planeta Terra. É possível lançar mão de uma ilustração das camadas da Terra, ou mesmo um modelo tridimensional em escala do planeta. São modelos, mas não possuem relações analógicas na sua concepção, apesar de possuírem similaridades com o DA que se objetiva representar. Mas seria possível a proposição de um modelo analógico para representar as camadas geológicas? Para tal, busca-se um domínio familiar - DB -, algo que faz parte do cotidiano dos envolvidos no processo de modelagem. Uma opção seria, por exemplo, propor uma comparação com uma laranja seccionada, a qual servirá como DB para a comparação por analogia. Nessa escolha, deve se levar em consideração que a laranja é algo existente na natureza, sem a intenção inicial de ser um modelo concebido para representar o planeta Terra; foi designado por possuir características analógicas com o DA que se quer representar. É importante levar em consideração as limitações que a escolha evoca, deixando claro que as distinções que existem entre os dois domínios. A Fig. 01 demonstra o processo de comparação analógica entre os dois domínios: 


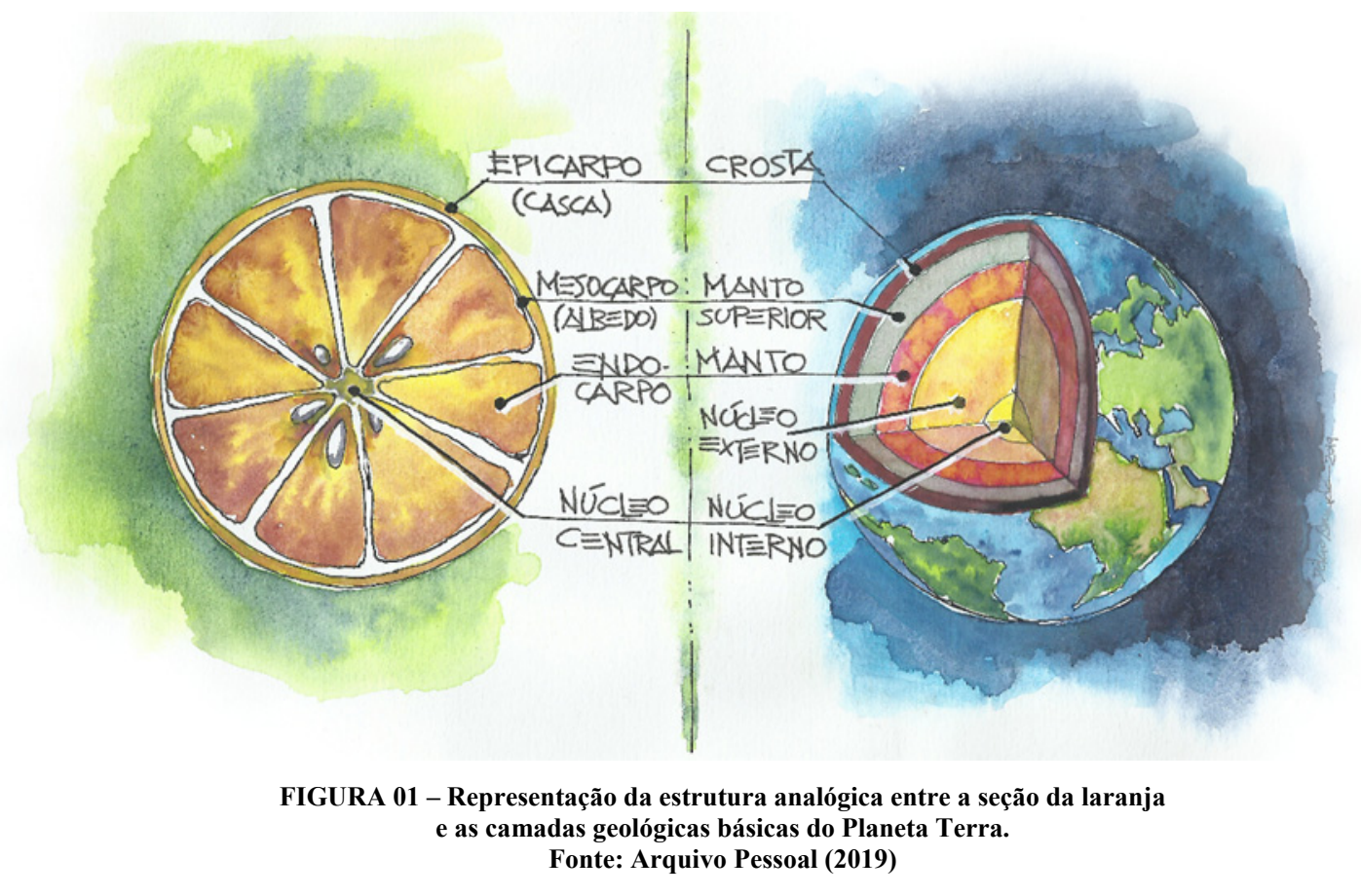

Ferry (2016) atenta para a dinâmica relacional que se observa nas dimensões envolvidas no processo de modelagem, apresentada no diagrama apresentado na Fig.2, é possível observar os conceitos de modelos, análogos e a entidades de interesse científico que se pretendem modelar:

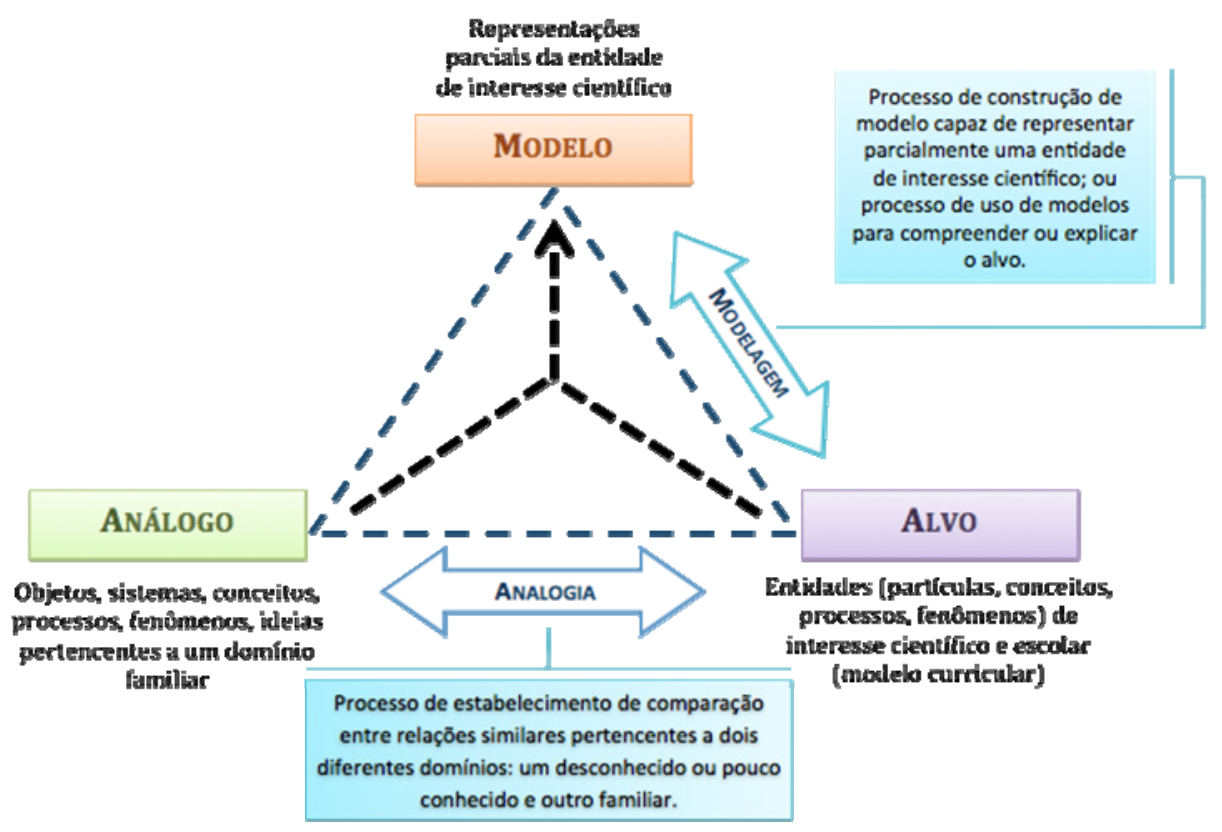

FIGURA 02 - Diagrama relacional entre os conceitos Modelos, Análogos e Alvo. Fonte: Ferry (2016)

De acordo com Gentner (1983), uma relação que se utiliza de analogias necessita que os domínios envolvidos possuam predicados que os caracterizem. Essas particularidades, em cada domínio, podem ser classificadas como elementos, atributos dos elementos, relações entre elementos e relações entre atributos dos elementos. Os elementos de um domínio são os componentes desse 
domínio, como sua estrutura física, cores, formas, dimensões dentre outros, que devem ser alinhados, contrapostos, com as formas, cores e dimensões do outro domínio envolvido na comparação. Por relações entre elementos e relações entre atributos dos elementos entende-se a maneira como se comportam esses elementos e como interagem, no processo de comparação analógica. Essas relações entre elementos são nomeadas como relações de primeira ordem, enquanto as relações entre relações são de segunda ordem ou ordem superior. Como exemplo, pode-se verificar a comparação do modelo atômico de Rutherford com um sistema solar (GENTNER \& MARKMAN,1997), sendo o modelo atômico o DA e o sistema solar o DB. Na comparação, é possível mapear elementos, como núcleo e elétrons no DA e a estrela central e os planetas no DB, além de seus predicados, como tamanho desses elementos e constituição desses elementos. Uma relação de primeira ordem pode ser observada no comportamento dos elétrons orbitando o núcleo do átomo da mesma forma que os planetas orbitam a estrela central. Uma relação de ordem superior é observada nos efeitos ou causas que o comportamento dos elementos gera nas suas relações de primeira ordem. Por exemplo, o movimento dos elétrons ao redor do núcleo se deve ao efeito de atração que o núcleo exerce sobre os elétrons, da mesma forma que o movimento dos planetas ao redor da estrela ocorre devido às forças de atração que ocasionam tal movimento. Portanto, a TME sugere que, para determinar a abrangência e as limitações de uma comparação por analogias, será necessário o mapeamento desses elementos, atributos e relações dos DA e DB. O mapeamento permite que se proceda a comparação entre os dois domínios.

Gentner (1983) afirma que quanto mais houver similaridades baseadas em relações, tanto de primeira ordem quanto de ordem superior, maior será a abrangência da comparação analógica entre os domínios alvo e base. A autora propõe uma tipologia de classificação do grau de sobreposição entre domínios, no sentido de direcionar a escolha dessas comparações. Primeiramente, quando se observa no mapeamento estrutural, a sobreposição de muitos elementos e atributos desses elementos, a comparação analógica será classificada como uma similaridade literal. Por exemplo, para se explicar as características da galáxia Via-Láctea, utiliza-se a comparação com galáxia de Andrômeda. Em seguida, tem-se a similaridade de mera aparência, observada quando ocorrem muitas sobreposições entre os atributos dos elementos e poucas sobreposições entre relações. Um exemplo de similaridade de mera aparência seria comparar o átomo de Dalton com uma bola de sinuca (FERRY, 2016). Dando continuidade à classificação tipológica, Gentner (1983) introduz o conceito de anomalia para classificar a comparação que, quando sobreposta, se observam poucos ou nenhuns atributos de elementos e relações. Ferry (2016) sugere, como exemplo, a comparação de um buraco negro como um ponto escuro em uma folha de papel. Finalmente, ocorrem as analogias, as quais possuem poucas sobreposições entre atributos de elementos e muitas relações alinhaveis entre os dois domínios. Como exemplo, pode-se citar a comparação do modelo atômico de Bohr com o Sistema Solar.

Deve-se levar em consideração que, apesar da classificação apresentada anteriormente, cada situação de comparação dependerá dos contextos sociais e históricos dos indivíduos envolvidos, posto que, dependendo do contexto, uma comparação que é considerada uma analogia, pode ser tomada como uma similaridade de mera aparência e assim por diante. Portanto, faz-se imprescindível o cuidado em não só considerar critérios lógicos e quantitativos para a escolha de características dos domínios que serão utilizados no processo de comparação (FERRY, 2016).

Resumidamente, portanto, foi apresentada a TME que, entretanto, devido ao limite do presente artigo, não permitirá um aprofundamento. Vale afirmar que a TME se refere ao mapeamento de analogias e sua aplicação em situação de ensino-aprendizagem de entidades de interesse científico. Dessa forma, a partir dos estudos desenvolvidos a partir dessa teoria, utilizadas para avaliar modelos analógicos destinados à divulgação da ciência (ALMEIDA, 2017; EMAR DE ALMEIDA et al, 2018), foi possível o seu desdobramento na Metodologia do Mapeamento Reverso - MMP, a qual pretende proporcionar uma ferramenta de criação para ser aplicada nos processos de design de estratégias de divulgação científica.

\subsection{A METODOLOGIA DO MAPEAMENTO PRÉVIO - MMP}

A Metodologia do Mapeamento Prévio surge a partir da demanda que se conceber uma ferramenta que potencialize o processo de criação de estratégias de design para a divulgação da ciência. Conforme foi discutido anteriormente, a divulgação da ciência ocorre com a utilização de vários meios, modelos e 
espaços, como museus de ciência, cinema, jornalismo científico dentre outros. Entretanto, discute-se o grau em que os profissionais envolvidos na concepção dessas estratégias levam em consideração as comparações analógicas utilizadas no processo, possuindo clareza em avaliar sua validade no processo comparativo. A importância em se discutir essa dinâmica é minimizar a possibilidade de equívocos epistemológicos provenientes de comparações pouco estruturadas. Apesar de não ser explicita na maioria das vezes, o papel do Design na concepção dessas estratégias se apresenta como ponto de atenção para o bom entendimento das intenções informacionais e construção do conhecimento esperados. Organizar a informação em museus de ciências, por exemplo, pode ser decisiva para a apreensão e despertamento do público para conceitos científicos (ALMEIDA, 2017).

Dessa forma, a MMP objetiva possibilitar o alinhamento do pensamento do Design e Ciência, no momento em que permite demonstrar que o exercício criativo não é uma área restrita ao profissional do Design e, em contrapartida, é possível que ocorra a interação com os profissionais da Ciência, além dos possíveis usuários, construindo, juntos, estratégias mais bem fundamentadas de divulgação científica. A proposta, portanto, foi a apropriação da estrutura do mapeamento estrutural para uma forma mais factível, mas não necessariamente menos criativa, que permita que os participantes do processo contribuam no processo de modelagem. A MMP se baseia na avaliação da relação analógica e a definição das características do modelo, trazendo à tona sua abrangência e suas possíveis limitações, tanto estruturais quanto funcionais e semânticas, no sentido de, inclusive, serem superadas ou aportadas por outros modelos e estratégias comunicacionais que a complementem.

Resumidamente, a MMP se baseia em algumas etapas fundamentais:

- Definição da equipe de modelagem

- Definição da entidade de interesse científico a ser modelada (domínio alvo)

- Definição da analogia (domínio base)

- Mapeamento Prévio

- Análise das limitações apontadas no mapeamento (funcionais, estruturais, semânticas)

- Elaboração da natureza formal do modelo a ser construído (sketch roughs, materiais, textos explicativos e possíveis modelos de apoio)

- Avaliação preliminar do modelo

- Prototipagem

- Verificação, junto ao público alvo, da eficácia do modelo

As etapas da MMP se organizam em um processo iterativo que será nomeado como Circuito Criativo de Modelagem, em que cada etapa permite o retorno à etapa ou etapas anteriores. Algumas das etapas podem ocorrer simultaneamente, não havendo, dessa forma, uma linearidade rígida no processo criativo.

O primeiro passo é a definição da equipe de modelagem. O objetivo é que essa equipe, orientada pelos profissionais de Design, seja composta por indivíduos com formação transdisciplinar, tanto por profissionais envolvidos no processo de divulgação científica ou ensino e aprendizagem pesquisadores e professores de ciências - assim como o próprio público-alvo a qual o produto resultante esteja direcionado.

A etapa inicial, referente à definição da entidade de interesse científico, é estruturada de maneira que permita a interação dos integrantes da equipe de criação. É a etapa relacionada à preparação do processo criativo, na qual os integrantes são instigados a compartilhar suas experiências com a área de interesse científico, no sentido de definirem qual entidade será escolhida para ser modelada. São listados os obstáculos que possivelmente se encontram no entendimento desse conhecimento científico, sua importância na construção do conhecimento e estratégias que são utilizadas para sua abordagem. Nesse momento, é solicitado aos participantes do processo que não excluam ou bloqueiem nenhuma das ideias que surjam na discussão, aos moldes da técnica de brainstorming, valorizando o pensamento divergente e abdutivo. Foi desenvolvido um formulário que apoie e contribua na organização dos insights preliminares do processo criativo, mas sugere-se que os participantes lancem mão de outras técnicas como mapas mentais, listagem de atributos ou outras técnicas criativas escolhidas pela equipe. É recomendado que se registrem as possíveis analogias que surjam na discussão. 
Após essa etapa inicial, é feita a escolha da analogia (DB) que será utilizada para a comparação com a entidade de interesse científico (DA) que será modelada. Vale lembrar que essa escolha não é definitiva, pois dependerá do resultado do mapeamento estrutural para avaliar sua adequação ao processo. Deve-se levar em consideração as sugestões de analogias que possam surgir na primeira etapa do processo criativo. Portanto, dependendo do resultado do mapeamento, é possível retornar ao processo de inicialização e se efetuar a escolha de outro DB. A equipe de criação contará com um formulário que facilitará o alinhamento entre os elementos, atributos de elementos, relações de primeira ordem e de ordem superior. Não há um limite quanto ao número de quadros que serão preenchidos, nem a possibilidade da utilização de outras técnicas de listagem dessas sobreposições. O importante é que sejam levantadas o maior número de relações de ordem superior entre DB e DA. Essa etapa é caracterizada pelo raciocínio dedutivo, partindo de generalizações para particularidades, em um processo convergente de pensamento. Essa etapa do mapeamento estrutural é o cerne da MMP, pois ela será primordial para a verificação da abrangência e limitações da sobreposição proposta.

Em seguida, tem-se a etapa de verificação das limitações do domínio base (elemento análogo) no que se refere às suas potencialidades representativas. É uma etapa de elaboração do processo criativo, momento em que a relação analógica passa por uma análise criteriosa de seus elementos, atributos e relações de ordem superior e primeira ordem, de forma que é possível propor estratégias que visem a superação de tais limitações ou mesmo a proposição de outros modelos alternativos. $\mathrm{O}$ levantamento das limitações pode levar à redefinição da DB. O raciocínio indutivo se faz presente, já que são estudadas as particularidades que caracterizarão o modelo, possibilitando a emersão de generalizações.

Portanto, após essas três etapas de diagnóstico dos DB e DA, segue-se o processo de concepção visual propriamente dito. Aqui, são propostos os primeiros sketch roughs, os possíveis materiais que poderiam ser utilizados na construção do modelo - caso a proposta seja a concepção de um modelo físico - estruturas de apoio, textos informativos, elementos áudio visuais, mockups, dentre outras. É importante perceber que, mesmo nesse momento, é possível o retorno às etapas anteriores, já que a MMP possui etapas iterativas, baseadas em feedbacks entre as mesmas. Igualmente importante é que a equipe submeta o mockup inicial a verificação de um grupo de controle. Técnicas de coleta de dados como Think Aloud Protocol, grupo focal, observação não participativa dentre outras, são recomendadas. Essa etapa é de extrema importância para que os ajustes ao projeto sejam feitos. Caso o retorno dessa primeira submissão seja positivo, parte-se para a etapa da prototipagem.

A etapa da prototipagem se refere à construção do modelo ou estratégia de comunicação, agora de forma mais estruturada, para a submissão pública. Entretanto, faz-se necessário a observação do parecer do usuário, pois ela determinará os possíveis ajustes e retorno à "prancheta de criação". Em caso de uma exposição científica, com o modelo inserido na mesma, deve-se observar o comportamento dos visitantes e recolher seu feedback quanto ao conteúdo explorado e a eficácia do modelo em representar a entidade de interesse científico alvo da representação. No caso de um modelo construído com o objetivo de ensino-aprendizagem, cabe aos envolvidos no processo de modelagem verificar, junto ao público discente, a eficácia do modelo na construção do conhecimento. Uma questão que deve ser levada em consideração é a possibilidade de se verificar o entendimento, a apreensão dos conceitos referentes à entidade de interesse científico que foi o alvo do processo de modelagem. Quais critérios devem ser utilizados para essa verificação, principalmente no caso de situações em que o produto de design, resultante da modelagem, estiver inserido em um espaço não formal de educação, ou ser utilizado para tal, como palestras, feiras ou mesmo em âmbito doméstico? Essas especificidades quanto aos objetivos do modelo determinam sua natureza, no momento em que não há como verificar aprendizagem em situações de divulgação científica em situações informais ou não formais. Em uma situação de sala de aula, com estrutura ementaria e grade curricular estruturada, existe um ambiente propício para essa verificação, o mesmo não ocorrendo em estratégias de divulgação científica. As ferramentas de verificação, neste caso, são mais subjetivas, um controle menos formal - não prescindindo, obviamente, de sistematização - ao contrário do que acontece em uma sala de aula. É possível verificar a estrutura esquemática da MMP na figura a seguir: 


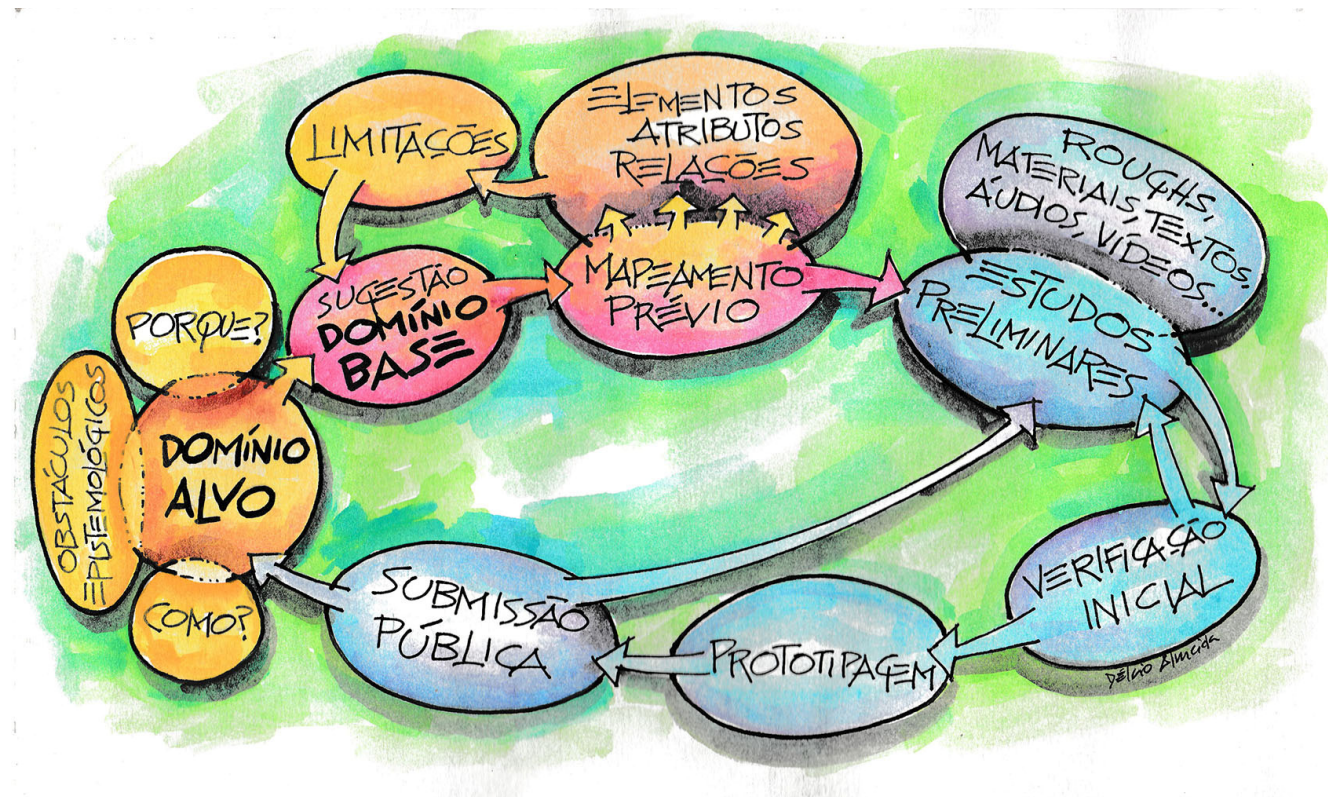

FIGURA 03 - Esquema do Circuito Criativo de Modelagem do MMP Fonte: Arquivo Pessoal (2019)

Uma particularidade do Circuito Criativo de Modelagem que deve ser destacada é o retorno ao conceito científico que se pretende modelar, ou seja, pretende-se a confrontação entre a percepção e entendimento do conceito científico com os conceitos anteriores dos sujeitos participantes do processo de modelagem, já que a dinâmica de modelagem, segundo Nersessian (2008), não se refere apenas à construção de modelos, mas antes a modificação de modelos preexistentes, assim como a adoção de novos modelos referentes à entidade de interesse científico. $\mathrm{O}$ raciocínio por analogias se apresenta como fundamental durante todo o processo de modelagem, favorecendo a argumentação e justificação, identificando e analisando criticamente evidências, clara e coerentemente (GILBERT e JUSTI, 2016). Portanto, a proposição do MMP permite que a reflexão a respeito das entidades de interesse científico possa favorecer a concepção de produtos de Design conceitualmente estruturados, instigando os participantes a aprofundarem no entendimento - no porquê e para que - dos princípios da Ciência, nos seus possíveis desdobramentos.

\subsection{A aplicação da MMP}

Será descrita, a seguir, a experiência da aplicação da MMP, objetivando validar na prática a metodologia, apontando mudanças de trajetória, ajustes e percepções. A aplicação da MMP contou com a participação de 26 professores e alunos das áreas diversas das ciências, em particular dos setores da saúde, além da orientação de um profissional de Design, em um encontro presencial. Os participantes inscritos não conheciam previamente do processo da MMP, mas foram informados que o objetivo era conhecer técnicas do Design que poderiam potencializar a tradução de conceitos científicos para um público não iniciado.

Inicialmente, após a divisão em 5 equipes, foi proposto aos integrantes que compartilhassem impressões a respeito dos conteúdos científicos que gostariam de abordar. Para tal, foi sugerido que discutissem a importância do tema, como normalmente é abordado e quais as dificuldades na abordagem.

Foi explicado o funcionamento das técnicas de brainstorming, mapa mental e sugerido que os participantes lançassem mão de outras estratégias que considerassem importantes. Em seguida, foi solicitado que buscassem comparações analógicas, sempre levando em consideração que essas analogias deveriam ser familiares aos públicos que pretendiam direcionar a entidade de interesse científico que iriam modelar. Assim que as equipes definiram as analogias, deu-se início ao processo de mapeamento estrutural. Devido ao limite de espaço no presente artigo, não serão descritas todas as 
5 propostas, mas vale destacar o domínio alvo sistemas gerados de estresse, cuja equipe desenvolveu a comparação analógica com a bomba nuclear. O tema escolhido se deve ao fato da equipe ser formada por profissionais, em sua maioria, com atuação na área da Psicologia e perceberem a necessidade de se discutir mais claramente os processos que acionam o estresse. Segundo a equipe, a relevância do tema mora na possibilidade da identificação do problema, aumentando as estratégias de auxílio, já que, com um maior entendimento dos processos de estresse, o indivíduo poderia se perceber na situação e buscar ajuda. Permitiria, ainda, a desestigmatização do tema, envolto que está de preconceito, resistências quanto à abordagem e, consequentemente, pouca visualização e disseminação do assunto.

A escolha da bomba nuclear, como domínio base, surgiu depois de alguns minutos de discussão, apoiada pelas técnicas de criação, no qual apareceram comparações com explosão, danos causados pela mesma, dentre outros. Portanto, os danos físicos, sociais, emocionais e financeiros causados pelo estresse se comparam com os danos causados pela bomba. A redução da produtividade consequente dos processos de estresse foram mapeados como similares à destruição da infraestrutura de uma cidade, reduzindo sua capacidade produtiva. As possíveis causas dos processos de esgotamento nervoso, como excesso de trabalho e estudo, desorganização do tempo e situações internas e externas, se comparam com os mesmos processos químico-físicos que acionam a explosão da bomba. As manifestações internas e externas de um indivíduo passando pelo processo de estresse se assemelham aos efeitos da radiação da explosão. Observou-se, portanto, que ocorreram mais alinhamentos entre relações de primeira ordem e de ordem superior, demonstrando a validade da comparação analógica, segundo Gentner (1983).

Por outro lado, igualmente foram apontadas limitações entre os dois domínios, o que possibilitou que se propusessem alternativas que contornassem tais limitações, ampliando a abrangência da comparação. Foi interessante observar que a equipe de criação, mesmo durante o processo de mapeamento estrutural, iniciou alguns esboços de possíveis estratégias visuais e de comunicação que poderiam ser utilizadas para representar cada relação de primeira ordem e ordem superior. O profissional de Design colaborou durante esse processo, auxiliando em formas de representação e técnicas que extrapolavam o conhecimento dos demais membros da equipe. Essa observação demonstra que a MMP não predispõe um processo linear rígido de concepção, permitindo iterações e avanços nas etapas. Essas várias intervenções e instigações foram cruciais para a emersão de propostas de modelos analógicos. Dentre as propostas apresentadas, foi escolhido um jogo de cartas, aos moldes de um jogo de tabuleiro, no qual os participantes acompanhariam o processo de surgimento, formação, explosão ou reversão do processo de estresse, baseado nas reações químicas de uma bomba nuclear. A proposição foi escolhida pois ela apresentava a possibilidade de abordar, de forma lúdica e com certa leveza, o tema delicado.

A etapa de estudos preliminares permitiu que os participantes detalhassem as características visuais e estruturais do jogo proposto, tendo o mapeamento como fonte conceitual para o processo criativo. Já que as abrangências e limitações foram previamente levantadas, houve a possibilidade de reduzir as incoerências e ambiguidades que poderiam advir das estratégias de comunicação. As relações de primeira ordem e as de ordem superior, por exemplo, permitiram a concepção de imagens, ícones e regras do jogo, de forma a instigar que os jogadores se percebessem no processo. De acordo com os participantes da equipe de modelagem, esse jogo poderia, inclusive, ser aplicado pelo terapeuta a seus pacientes, no sentido de avaliar de possíveis sintomas grau de estresse, e igualmente ser utilizado como estratégia de ensino para estudantes de Psicologia.

Devido ao tempo limitado da oficina, não foi possível dar a continuidade no processo de estruturação da proposta do modelo. Os integrantes das equipes, inclusive, foram unânimes em apontar como um ponto negativo as 4 horas disponíveis para a oficina, consideradas insuficientes para a concepção da proposta. Discute-se a necessidade de um período de incubação das ideias, maior preparação dos integrantes, como pesquisas a respeito do tema e busca de estratégias similares. A FIG.4 apresenta algumas das etapas do processo da MMP: 


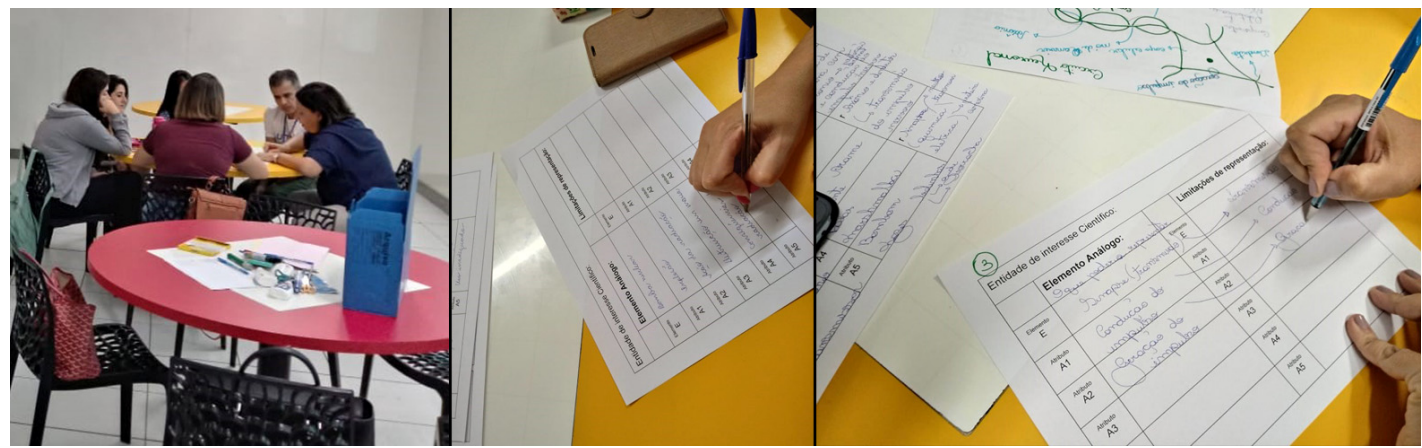

FIGURA 04 - Momentos do Circuito Criativo de Modelagem do MMP

Fonte: Arquivo Pessoal (2019)

A experiência com a equipe de criação demonstrou que a MMP, com um prazo maior de aplicação e desenvolvimento, pode auxiliar na concepção de estratégias criativas de Design que objetivam a divulgação científica. A sistematização do processo do uso de analogias para a construção do conhecimento evidencia-se na organização da dinâmica metodológica, ampliando a reflexão e aprofundamento na análise das entidades de interesse cientifico que se pretendem popularizar. Outro ponto observado é a indiscutível característica interdisciplinar da equipe, que potencializou a emersão do produto criativo. O compartilhamento de saberes, visões de mundo, especialidades e habilidades foi crucial para a eficácia da dinâmica, enriquecendo o processo. A aplicação da MMP nesse teste piloto possibilitará correções e ajustes na estrutura metodológica, a qual será avaliada em testes posteriores.

\section{CONSIDERAÇÕES FINAIS}

A proposição da Metodologia do Mapeamento Prévio intenciona a interação interdisciplinar, no sentido da proposição de produtos transdisciplinares nas dinâmicas de concepção de estratégias de design para a divulgação científica. A área de atuação do Design se caracteriza, portanto, como mediadora nesses processos, reduzindo possíveis obstáculos epistemológicos que possam surgir nas situações em que se pretende traduzir ou recriar conceitos científicos para um público não iniciado.

Apesar do objetivo dessa pesquisa não era abordar as dinâmicas relacionadas aos processos de ensino/aprendizagem - os quais requereriam outras abordagens teóricas e procedimentos de investigação e análise - observa-se que a estratégia da MMP favorece não só favorece à concepção de produtos de Design destinados à divulgação científica, como igualmente pode ser ampliado para a sala de aula, necessitando, entretanto, de outras investigações. Dessa forma, observa-se que, compartilhar conhecimentos, vivências e visões de mundo entre profissionais das áreas da Ciência e do Design podem contribuir para a emersão de produtos visuais e informacionais que potencializem o interesse pelos conceitos científicos. A MMP também possibilita a participação do usuário do produto do Design, o que, de alguma forma, pode ampliar a dimensão dos significados e popularização da Ciência. Argumenta-se que ouvir as demandas do público, por meio de soluções de Design, ampliará os espaços de debate quanto os impactos do fazer da Ciência na sociedade, modificando conceitos estereotipados e equivocados. Dessa forma, a formação de sujeitos atuantes nas questões relacionadas a esses conceitos científicos e tecnológicos apresenta-se como ponto imprescindível na construção da cidadania. 
The performance of design in scientific dissemination processes: the Methodology of Prior Mapping

Abstract: This article discusses the role of Design in the processes of building scientific dissemination strategies. Definitions of what is the dissemination of science, its relationship with Design and the intersections between the methodological processes that characterize the areas of both Design and Science are presented. To this end, the proposal of the Methodology of Prior Mapping will be presented, developed from the Theory of Structural Mapping belonging to the area of cognitive psychology, initially conceived to analyze the scope and limitations of analogies, used in teaching and learning processes. Thus, it is proposed to unfold the mapping of analogical relations for the design of models for the dissemination of scientific concepts. Preliminary results of the application of this methodology will be presented.

Keywords: Design, Methodology of Prior Mapping, scientific dissemination, project methodologies, Structural Mapping Theory

\section{Referências bibliográficas}

ALBAGLI, S. Divulgação Científica: informação científica para a cidadania? Ciência da Informação, Brasília: 1996

ALEXANDRE, R. F.; REIS, A. L. P.; NOVAES, L. Reflexões sobre Design e iniciativas participativas no contexto museal. Design \& Tecnologia: UFRGS. 2019

ALMEIDA, R. B. S. Analogias e modelos: construção de objetos museais para a divulgação científica. 120 f. (Dissertação de Mestrado apresentada ao Programa de Pós-graduação em Educação tecnológica) - Centro Federal de Educação Tecnológica de Minas Gerais CEFET-MG, Belo Horizonte. 2017

BOZELLI, F. C.; NARDI, R. Interações discursivas e o uso de analogias no ensino de Física. Investigações em Ensino de Ciências. v.17(1). p. 81-107, 2012

BUCHANAN, R. Design Research and the New Learning. Design Issues: Volume 17, Number 4 Autumn 2001

BUENO, W. C. Jornalismo científico no Brasil: aspectos teóricos e práticos. ECA/USP. São Paulo: 1988

CAMPOS, Ana Paula. Inventório: Processos de divulgação científica para crianças - estudo de caso de livro informativo (Dissertação de Mestrado apresentado à Faculdade de Arquitetura e Urbanismo da Universidade de São Paulo - área de concentração: Design e Arquitetura) USP. São Paulo: 2016

COSTA Jr, H. G. O Design como estratégia de divulgação científica: o caso da FAPEMIG in Divulgação Científica: novos horizontes. Fagundes, V \& Silva Jr, M. G. (orgs.). Mazza Edições. Belo Horizonte: 2017

EMAR DE ALMEIDA, D. J.; ALMEIDA, R.B.S; FERRY, A.S. MAES-3DMF: mapeamento estrutural de um Modelo Analógico do Espaço Sideral 3D em Meio Fluido para o ensino de Ciências. Latin American Science Education Research Association - LASERA. Costa Rica: Latin American Journal of Science Education, v.5, 2018. Disponível em: http://www.lajse.org/nov18/2018_22004.pdf

FERRY, A. S. Análise Estrutural e Multimodal de Analogias em uma Sala de Aula de Química. 2016. 170 f. (Tese de Doutorado em Educação). Faculdade de Educação, Universidade Federal de Minas Gerais. Belo Horizonte. 
FERRY, A. S. (Org) Pesquisas sobre Analogias no contexto da Educação em Ciências à Luz da Teoria do Mapeamento Estrutural (Structure-mapping theory). -Editora Livraria da Física. São Paulo: 2018

GENTNER, D. Structure-mapping: A theoretical framework for analogy. Cognitive Science. 1983

GENTNER, D.; MARKMAN, A. B. Structure-mapping in analogy and similarity. American Psychologist, 52:45-56. 1997

Gilbert, J. K.; Justi, R. Modelling-based Teaching in Science Education. Basel, Switzerland: Springer International Publishing. 2016

GLYNN, Shawn. Teaching science with analogy: a strategy for teacher and textbook authors. Reading Research Report, USA (National Reading Research Center. Universities of Georgia and Maryland) n. 15, 1994

GOMBRICH, E. H. Arte e Ilusão: um estudo da psicologia da representação pictórica. 3. ed. Martins Fontes. São Paulo: 1995

MARANDINO, Martha; DÍAZ ROCHA, Paulo Ernesto. La biodiversidad en exposiciones inmersivas de museos de ciencias: implicaciones para educación en museos. Enseñanza de las Ciencias, 29(2), p. 221-236. 2011

MORA, A. M. S. A Divulgação Científica como Literatura. Casa da Ciência Editora, UFRJ. Rio de Janeiro: 2003

MORIN, E. Introdução ao pensamento complexo. Traduçã: Eliane Lisboa. 5. Ed. -Sulina. Porto Alegre: 2015

MOZZER, N. B.; JUSTI, R. Nem tudo que reluz é ouro: Uma discussão sobre analogias e outras similaridades e recursos utilizados no ensino de Ciências. Revista Brasileira de Pesquisa em Educação em Ciências, v. 15, n. 1, p. 123-147. 2015

NAGEM, R. L.; CARVALHARES, D.; DIAS, J. A. Uma proposta de metodologia de ensino com analogias. Revista Portuguesa de Educação, v. 14, n. 1. p. 197-213, 2001

Nersessian, N. J. Creating Scientific Concepts. MIT. Cambridge: 2008

OLIVA, J. M.; NAVARRETE, A; AZCÁRATE, P. Las analogías como recurso en la clase de ciencias: distintos perfiles docentes. Enseñanza de las ciencias, Número Extra, VII Congreso, 2005

PASSOS, P.C. S. J; PASSOS, J. E.; VANS, S. A. S.; CAREGNATO, S. E. Design e Comunicação Científica: um estudo a respeito da evolução das ciências e das revistas científicas. Congresso Brasileiro de Pesquisa e Desenvolvimento em Design - P\&D. Gramado: 2014

PEIRCE, C. S. Semiótica. Editora Perspectiva. S. Paulo:2005

PEREIRA, C.; SOUZA, A.; FRANQUEIRA, T. Comunicação visual: imagens que disseminam a ciência. Ergotrip Design - Revista dos Encontros Internacionais de Estudos Luso-brasileiros em Design e Ergonomia. 2015.

PIASSI, L. P. C.; SANTOS, C. C.; SANTOS, E. I. Ciência e Comunicação: a divulgação científica através de artefatos culturais no projeto "Banca da Ciência". XXXVI Congresso Brasileiro de Ciências da Comunicação - Intercom - Manaus, AM - 4 a 7/9/2013.

POPPER, K. R. A lógica da pesquisa científica. Cultrix. São Paulo: 2006

QUELHAS, A. C.; JUHOS, C. A psicologia cognitiva e o estudo do raciocínio dedutivo no último meio século. in Revista Análise Psicológica - ISPA - Instituto Universitário: Portugal, 4 (XXXI): p. 359-375. 2013

SILVA, H. C. O que é divulgação cientifica. Ciência \& Ensino, vol.1, n.1, 2006

SILVA Jr. M. G. Edição e (trans)criação do discurso especializado na revista Minas Faz Ciência. In Divulgação Científica: novos horizontes. Fagundes, V \& Silva Jr, M. G. (orgs.). Mazza Edições. Belo Horizonte: 2017 
TARGINO, M. G. Comunicação científica: uma revisão de seus elementos básicos. Fundamentado na tese de doutorado: Comunicação científica: o artigo de periódico nas atividades de ensino e pesquisa do docente universitário brasileiro na pós-graduação, defendida junto à Universidade de Brasília, Brasília - DF, em 14/12/1998.

TERRAZZAN, E. A. et al. Estudo das analogias utilizadas em coleções didáticas de física, química e biologia. Enseñanza de las Ciencias, NEC/CE/Universidade Federal de Santa Maria. Brasil, Número Extra, VII Congreso, 2005. 